(1969). A productive cough upon request as an index of chronic bronchitis: the effects of age, sex, smoking habit and environment upon prevalence in Australian general practice. Med. J. Aust., 1, 16.

- and MILNE, J. (1965). Ventilatory capacity in response to jute dust and the relevance of productive cough and smoking to the response. Brit. J. industr. Med., 22, 187.

-, and RitchiE, B. (1966). Relevance of respiratory symptoms and signs to ventilatory capacity changes after exposure to grain dust and phosphate rock dust. Brit. J. industr. Med., 23, 181.

Gibson, H. B., Silverstone, H., Gandevia, B., and HALL, G. J. L. (1969). Respiratory disorders in sevenyear-old children in Tasmania. Aims, methods and administration of the survey. Med. J. Aust., 2, 201.

Hong, C. S., Gandevia, B., and Lovell, H. (1967). Ventilatory capacity in a series of male adults and the effect of respiratory symptoms, productive cough, smoking habit and occupation. Med.J. Aust., 1, 169.

\title{
REVISION OF THE INTERNATIONAL CLASSIFICATION OF DISEASES
}

The World Health Organization has started its 10yearly process of revision of the International Classification of Diseases, Injuries and Causes of Death (ICD) to bring it into line with current needs. The classification is the one used throughout the world in official statistics of mortality and morbidity and is also widely used for indexing records such as hospital case notes.

Although the next revision, the ninth, will not come into use until 1978, the Revision Conference which will decide its details will be convened by the World Health Organization in 1975, and the end of 1972 is the last date for national proposals to reach them.

The World Health Organization has decided that the basic structure of the ICD shall remain the same at this revision (though a more fundamental revision is not ruled out for the future) and that the numbering system shall not be disturbed without good reason, such as when part of the classification is so out of date as to warrant complete restructuring of that part. But it is recognized that extra detail must be provided by subdivision for those who need it in applications such as hospital indexing.

The Director and Registrar General has appointed a subcommittee of his Medical Advisory Committee to advise on the United Kingdom proposals and also to advise the WHO Centre for the Classification of Diseases, in this department, on tasks which it has been allotted in connexion with the revision. The subcommittee will appoint working groups of specialists in the various fields.

The committee would welcome comments or proposals from anyone with an interest in the subject and would be glad to know, early, of any proposed work.

We have been asked to publish the above note by Dr. A. M. Adelstein, Chief Medical Statistician at the Office of Population Censuses and Surveys, Somerset House, London, W.C.2. 